\title{
The Pattern of Peroxisome Proliferator-activated Receptor Gamma Coactivator 1-alpha Gene Expression in Type-2 Diabetes Mellitus Rat Model Liver: Focus on Exercise
}

\author{
Yetty Machrina $^{1 *(D)}$, Dharma Lindarto ${ }^{2}$ (D), Yunita Sari Pane ${ }^{3}$ (D) Novita Sari Harahap ${ }^{4}$ (D) \\ ${ }^{1}$ Departement of Physiology, Faculty of Medicine, Universitas Sumatera Utara, Medan, Indonesia; ${ }^{2}$ Departement of Internal \\ Medicine, Faculty of Medicine, Universitas Sumatera Utara, Medan, Indonesia; ${ }^{3}$ Departement of Pharmacology, Faculty \\ of Medicine, Universitas Sumatera Utara, Medan, Indonesia; ${ }^{4}$ Departement of Sport Medicine, Faculty of Sport Medicine, \\ Universitas Negeri, Medan, Indonesia
}

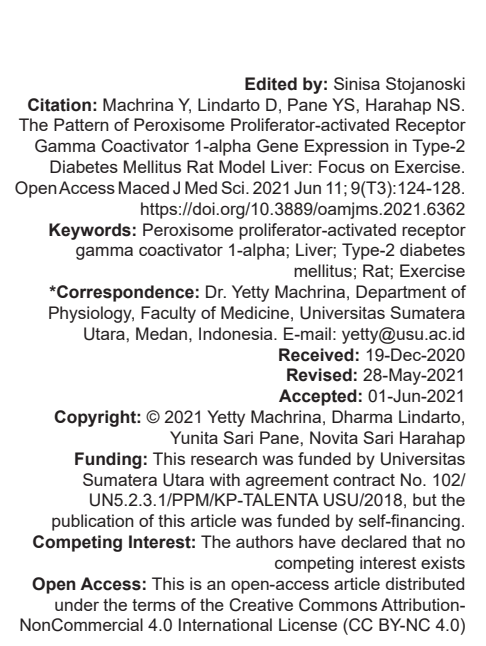

\section{Abstract}

BACKGROUND: Peroxisome proliferator-activated receptor gamma coactivator 1-alpha (PGC-1 $\alpha$ ) has an important role in mitochondria biogenesis which generated cellular metabolism. Carbohydrate metabolism in the liver is crucial to maintain plasma blood glucose.

AIM: This research aimed to determine the expression of PGC-1 $\alpha$ gene in the liver type-2 diabetes mellitus (T2DM) rat model, after treatment with a focus on exercise.

METHODS: We used 25 healthy male Wistar rats as subjects. Rats were modified to T2DM models by feeding a high-fat diet and low-dose streptozotocin injection. We divided the rats into five groups, that is, sedentary group as a control and four others as treatment groups. The exercise was assigned for treatment groups by a run on the treadmill as moderate intensity continuous (MIC), highintensity continuous (HIC), slow interval (SI), and fast interval $(\mathrm{FI})$. The treatment groups were exercise throughout 8 weeks with a frequency of 3 times a week.

RESULTS: The results showed that expression of PGC- $1 \alpha$ gene was lower in all treatment groups compared to controls $(p<0.05)$. Expression in HIC was higher than MIC $(p<0.05)$, so was the expression in FI more than SI $(p<0.05)$.

CONCLUSIONS: Exercise affected PGC-1 $\alpha$ gene expression in the liver of the T2DM rat model. The expression of PGC-1 $\alpha$ was linear with exercise intensity.

\section{Introduction}

The prevalence of Type-2 diabetes mellitus (T2DM) has been growing in Indonesia. The World Health Organization estimated that the prevalence will still rise until 2030. Indonesian Health Ministry has reported that the prevalence of T2DM rose from $6.9 \%$ in 2013 to $8.5 \%$ in 2018 . This phenomenon correlated with lifestyle change on diet and physical activity in Indonesian people, where the data show that people with physical inactivity in Indonesia increased by $33.5 \%$ in 2018 [1], [2]. Lack of physical activity, nutrient excess, and obesity influenced DNA methylation including peroxisome proliferator-activated receptor (PPAR)-1 alpha coactivator (PGC-1 $\alpha$ ) activity as a key regulator of cellular energy metabolism. This condition was an important risk factor for insulin resistance (IR) [3], [4].

PPAR PGC- $1 \alpha$ is a protein complex that increases the probability of a gene being transcribed by interacting with transcription factors such as Forkhead box 01, glucocorticoid receptor, and hepatic nuclear factor- $4 \alpha$. By regulating the activities of these transcription factors, PGC- $1 \alpha$ acts as a molecular switch for multiple cellular processes, including mitochondrial biogenesis and respiration, gluconeogenesis. In gluconeogenesis, PGC-1 $\alpha$ binds to the promoter region from genes that encode enzymes gluconeogenesis such as phosphoenolpyruvate carboxykinase and glucose-6phosphatase (G-6-Pase) in the liver [5], [6], [7].

The liver is a crucial organ to maintain glucose homeostasis. Blood glucose concentration is mainly determined by glucose absorption at intestine, gluconeogenesis by the liver, and glucose utilization by skeletal muscle. In this process, the liver acts as a glucose reservoir that balances the glucose storage and release. Impaired hepatic glucose uptake and excessive hepatic glucose production are partially responsible for hyperglycemia in T2DM [8]. PGC-1 $\alpha$ is a downstream sensor of metabolic, hormonal, and 
inflammatory signals that are responsible for the balance of hepatic gluconeogenesis, fatty acid $\beta$-oxidation, and mitochondrial biogenesis [9].

Thepreviousstudieshavefound thatmitochondrial dysfunction is one of the causes of decreasing fatty acid oxidation, which plays a role in the pathogenesis of IR and T2DM [8], [10], [11]. Mitochondrial dysfunction is known to produce excessive reactive oxidative stress (ROS) that eventually leads to oxidative stress and pancreatic $\beta$-cell dysfunction. ROS as a result of oxidative stress mitochondrial decreased PGC-1 $\alpha$ expression and reduced glucose-stimulated insulin secretion [12]. Expression of PGC-1 $\alpha$ gene also found decreased in skeletal muscle so that muscle glucose uptake was disrupted, meanwhile, gene expression in the liver increased as compensation for the lack of cellular energy in T2DM [13], [14]. PGC-1 $\alpha$ expression modification might be a candidate for the management of mitochondrial dysfunction, leading to the treatment for diabetes mellitus [13], [15].

Few studies have been conducted to find out the effect of exercise on PGC- $1 \alpha$, especially at skeletal muscle [13], [16]. Studies proved that exercise could decrease plasma blood glucose and IR by improving mitochondrial function in T2DM patients [17], [18]. However, there was still limited information about the effect of exercise with different intensity to the expression of PGC-1 $\alpha$ liver gene. As we know that liver is also a homeostatic organ for blood glucose regulation and PGC-1 a promote mitochondrial biogenesis in gluconeogenesis. The aim of this research was to determine the expression of PGC-1 $\alpha$ liver gene in T2DM rats model with a focus on exercise that was carried out as continuously and interval with different intensity.

\section{Methods}

\section{Animal model}

This research was carried out using T2DM model rat (Rattus norvegicus sp.) as the subjects. Eight weeks of age Wistar were made T2DM by combining the administration of a high-fat diet and low-dose streptozotocin injections twice (30 mg/kg BW and $45 \mathrm{mg} /$ $\mathrm{kg} \mathrm{BW}$ in 0.1 citrate buffer $\mathrm{pH} 4.5$ given intraperitoneal). T2DM was determined if fasting blood glucose $<200 \mathrm{mg} / \mathrm{dl}$ and homeostatic model assessment-IR $($ HOMA-IR) $>6.5$. Cage placement, feeding and drinking of the subjects was done in accordance with the ethics approval of research in experimental animals.

\section{Animal intervention}

We intervened subjects with exercise ran on the treadmill as moderate-intensity continuous (MIC), high-intensity continuous (HIC), slow interval (SI), and fast interval $(\mathrm{FI})$ while the control group was made sedentary. Exercise intensity determination based on protocol of Huang et al. (Table 1). Exercise was carried out every 2 days with 30 min each session, for 8 weeks. Plasma blood glucose and HOMA-IR were assessed before and after exercise procedure. All rats were terminated under sedation (ketamine $30 \mathrm{mg}$ intramuscular) subsequent the intervention. Duration and intensity for each treatment groups are shown in Table 1.

Table 1: Duration and intensity of exercise for each treatment group

\begin{tabular}{ll}
\hline Groups & Exercise procedure \\
\hline MIC & $25 \mathrm{~m} / \mathrm{min}, 30 \mathrm{~min}$ \\
HIC & $30 \mathrm{~m} / \mathrm{min}, 30 \mathrm{~min}$ \\
SI & $25 \mathrm{~m} / \mathrm{min}, 10 \times 2 \mathrm{~min}, 1 \mathrm{~min}$ interval \\
FI & $30 \mathrm{~min}, 15 \times 30 \mathrm{~s}, 1 \mathrm{~min}$ interval \\
\hline MIC: Moderate-intensity continuous, HIC: High-intensity continuous, SI: Slow interval, Fl: Fast interval.
\end{tabular}

\section{mRNA PGC-1 $\alpha$ examination}

About 20-30 mg liver tissue was mixed with $\beta$-mercaptoethanol $10 \mu \mathrm{l}+1 \mathrm{ml}$ buffer RLT as much as $600 \mu \mathrm{l}$ and homogenized with a mortar. RNA isolation procedure followed RNeasy Mini Kit (Qiagen, Germany). Two microliters template RNA, two-step Sybr Green reagent, primer PGC-1 $\alpha$ forward and reverse, and beta-actin primer forward and reverse were mixed in $0.2 \mathrm{ml} \mathrm{PCR}$ tube. Rotor gene was setting; hold $95^{\circ} \mathrm{C}(2 \mathrm{~min})$, denaturation $95^{\circ} \mathrm{C}(5 \mathrm{~s})$, and annealing $60^{\circ} \mathrm{C}(30 \mathrm{~s})$ for 40 cycles. Cycling threshold from each group both target and reference gene was taken. Delta-delta $\mathrm{C}_{\mathrm{T}}$ was calculated by livask method to determine whether the expression higher or lower than control.

\section{Blood glucose and IR examinations}

Blood from rat vein tail was taken for about 2-3 $\mathrm{ml}$ then centrifuged at $6.000 \mathrm{rpm}$ for $3 \mathrm{~min}$ for serum isolation. Blood glucose level was assessed by spectrophotometer and insulin assessed with ELISA method followed Qia-Byee procedure. IR was determined by calculate fasting insulin $(\mathrm{U} / \mathrm{ml}) \times$ fasting plasma glucose $(\mathrm{mmol} / \mathrm{I}) / 22.5$ and named as HOMA-IR.

\section{Statistical analysis}

Data normality was confirmed using ShapiroWilk test. Plasma blood glucose and HOMA-IR before and after intervention in treatment groups were analyzed with dependent t-test. To find out whether the PGC-1 $\alpha$ gene mRNA expression in each group was significantly different, the cycling threshold of each group was analyzed with one-way ANOVA test and followed by post hoc least significant difference (LSD) to analyze the different between groups. Data were significant if $p<0.05$ was considered. 


\section{Results}

\section{mRNA PGC-1 $\alpha$ gene expression}

The average of cycling threshold of each group and gene expression compared to control is shown in Table 2. The cycling threshold value is opposite with gene expression. The extended cycling threshold time showed decreased of gene expression otherwise shorter cycling threshold mean gene expression increase.

Table 2: The average cycling threshold of each group

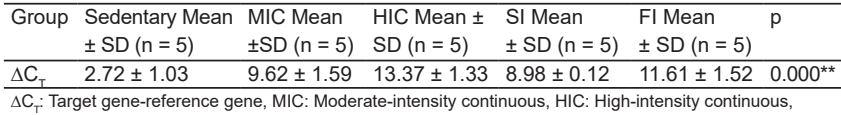

From Table 2, we found that time of cycling threshold value mRNA PGC-1 $\alpha$ gene at treatment groups was significantly different than control after 8 weeks of exercise $(p<0.05)$. Post hoc LSD analysis showed that differences in the length of the cycling threshold between groups were seen in the MIC group with HIC $(p=0.004)$, HIC with SI $(p=0.01)$, and SI with FI $(p=0.016)$, as shown at Figure 1. Calculation with livask method shown that 8 weeks of exercise were able to decrease the expression of mRNA PGC-1 $\alpha$ gene in liver T2DM rat model, $\mathrm{MIC}=0.0084, \mathrm{HIC}=0.0006$; $\mathrm{SI}=0.0130 ; \mathrm{FI}=0.0023$.

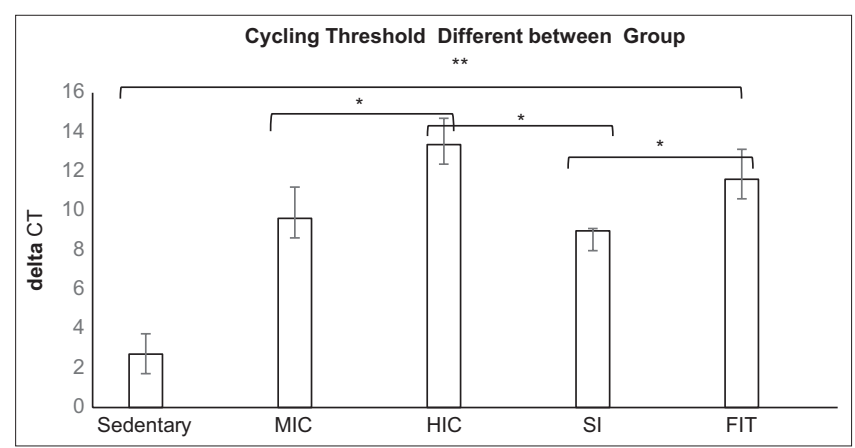

Figure 1: Cycling threshold showed significantly different between moderate intensity and high intensity. Moderate-intensity continuous (MIC)-high-intensity continuous (HIC) ( $p=0.004)$; MIC-slow interval (SI) $(p=0.311) ;$ MIC-fast interval (FI) $(p=0.098) ;$ HIC-SI $(p=0.01)$

\section{Blood glucose and IR}

Fasting blood glucose and IR in treatment groups before and after exercise assignment are shown in Table 3. Fasting blood glucose each treatment group after exercise assignment was significantly declined, as well as HOMA-IR except HOMA-IR in MIC group.

The magnitude of decreasing in fasting plasma glucose and IR after exercise protocol is shown in Figure 2.
Table 3: Plasma blood glucose and insulin resistance in treatment groups before and after exercise assignment

\begin{tabular}{llll}
\hline Groups & Pre-test & Post-test & p-value \\
\hline Blood glucose & & & \\
MIC & $339 \pm 103.7$ & $191.6 \pm 5.4$ & $0.014^{*}$ \\
HIC & $396.8 \pm 25.7$ & $198.2 \pm 75$ & $0.009^{*}$ \\
SI & $452.6 \pm 31.3$ & $227.2 \pm 87.8$ & $0.001^{*}$ \\
FI & $451.2 \pm 83.2$ & $259 \pm 25$ & $0.006^{*}$ \\
HOMA-IR & & & \\
MIC & $90.5 \pm 40.5$ & $43.3 \pm 8.6$ & 0.066 \\
HIC & $81.3 \pm 6.1$ & $18.5 \pm 6.4$ & $0.000^{*}$ \\
SI & $94.0 \pm 21.1$ & $16.6 \pm 4.0$ & $0.001^{*}$ \\
FI & $91.1 \pm 19.7$ & $19.7 \pm 7.8$ & $0.004^{*}$ \\
\hline${ }^{*} p<0.05$, MIC: Moderate-intensity continuous, HIC: High-intensity continuous, Sl: Slow interval, FI: Fast
\end{tabular}

interval HOMA-IR. Homeostatic model assessment-insulin resistance.

\section{Discussion}

The purpose of this research was to determine the expression of PGC-1 $\alpha$ gene in liver of T2DM rat model after treatment with a focus on exercise that was carried out as continuously and interval with different intensity. Our research found that expression of PGC-1 $\alpha$ gene in the liver was lower in exercise groups compared sedentary group. It was shown that exercise has an effect on PGC-1 $\alpha$ gene expression in the liver. This research is in line with Safdar et al. that endurance exercise alters biogenesis of mitochondrial by enhancing PGC-1 $\alpha$ function in mitochondria [17]. Meanwhile, Buler et al. found that PGC-1 $\alpha$ has beneficial effect of physical exercise and caloric restriction and becomes a regulatory interlink between energy homeostasis and the hepatic immune system [18] and improved mitochondrial dysfunction [19].

The expression of PGC- $1 \alpha$ gene in the liver after exercise was contrast with the expression in skeletal muscle. A previous research has proven that PGC-1 $\alpha$ expression has been reported to be increased in the liver of both Type 1 and Type 2 diabetic mouse models, in contrast to the reported observations that PGC-1 $\alpha$ expression was decreased in the muscle of human Type 2 diabetic subjects [13]. The influence of exercise on both expressions is reverse. Exercise increased PGC-1 $\alpha$ gene in skeletal muscle while decreased in liver [17], [20].

Increased hepatic PGC-1 $\alpha$ expression could be expected to stimulate hepatic glucose output in T2DM concerned with the default of plasma glucose to enter the cell [21]. Impaired insulin signaling in the liver disrupts the mechanism of glycogenesis and stimulates gluconeogenesis and glycolysis [22]. Induction of PGC- $1 \alpha$ and PGC- $1 \beta$ expression in liver is a critical regulatory event leading to the activation of energy metabolic pathways that serve to increase ATP production by fatty acid oxidation and exert homeostatic control, especially in fasted state as it is observed in diabetes mellitus. Moreover, PGC-1 $\alpha$ may promote IR directly by inducing TRB3 , an inhibitor of Akt signaling, a critical downstream component of the insulin signaling pathway, 


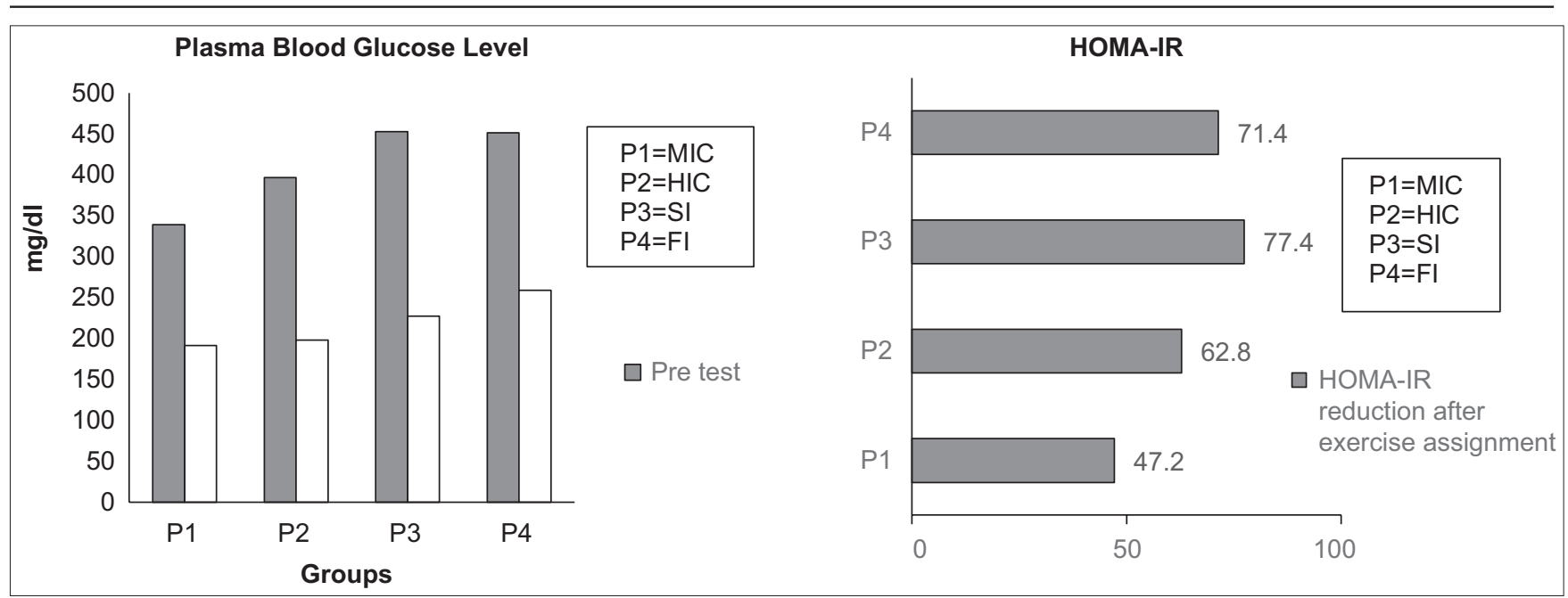

Figure 2: Plasma blood glucose and insulin resistance before and after 8 weeks of exercise. Reduction plasma blood glucose in moderateintensity continuous (MIC) group decreased as much as $147.2 \mathrm{mg} / \mathrm{dl}$, high-intensity continuous $(\mathrm{HIC})=198.6 \mathrm{mg} / \mathrm{dl}$, slow interval $(\mathrm{SI})=$ $225.4 \mathrm{mg} / \mathrm{dl}$, fast interval $(\mathrm{Fl})=192.2 \mathrm{mg} / \mathrm{dl}(\mathrm{A})$. Meanwhile, homeostatic model assessment-insulin resistance in MIC group decreases as much 47.2 HIC $=62.8, \mathrm{SI}=77.4, \mathrm{FI}=71.4$

potentially increasing hepatic glucose production that contributes to circulating hyperglycemia. Exercise has been shown improved IR in the liver by reducing the inflammatory process, including the inhibition of TRB3, and suppressing gluconeogenesis [23].

Exercise enhanced mitochondrial biogenesis to produce energy for muscle needs. Increased activity of mitochondrial enzymes and nitric oxide of the muscle stimulates PGC- $1 \alpha$ being more active [24]. This mechanism impacts insulin sensitivity in skeletal muscle and liver so that IR and plasma blood glucose were decreased [25]. Improvement in IR degrades liver gluconeogenesis, $I R$, and activated Akt signaling so that the PGC- $1 \alpha$ gene in liver was decreased [26].

In this research, PGC-1 $\alpha$ liver gene expression in HIC training was lower than in MIC so that the expression of PGC-1 $\alpha$ in $\mathrm{FI}$ was lower than SI. In vigorous intensity, cell metabolism produces more energy that promotes insulin sensitivity improvement at skeletal muscle [27]. Decreasing $\mathrm{IR}$ at skeletal muscle followed by decreasing on liver gluconeogenesis [28]. This finding suggests a connection between PGC-1 $\alpha$ liver gene expression and exercise intensity.

\section{Conclusions}

We conclude that exercise affected PGC- $1 \alpha$ gene expression in the T2DM rat model liver. The expression was associated with exercise intensity, especially in continuous exercise. We suggested advanced research to obtain more insight into the mechanism.

\section{Declarations}

\section{Authors' contributions}

$\mathrm{YM}$ and $\mathrm{DL}$ designed the research. $\mathrm{YM}$ and YSP collect data, YM and NSH analyzed the data. YM wrote the original draft of the manuscript, and all authors contributed to the concept and also all revised drafts of the manuscript. All authors read and approved the final version of manuscript.

\section{Acknowledgment}

The authors are grateful to head of animal laboratory department pharmacology, Faculty of Medicine, Universitas Padjadjaran, and the animal laboratory assistants for their cooperation in animal husbandry.

\section{Ethical approval}

This research has obtained ethical approval from medical faculty and RSUP H. Adam Malik Medan ethic committee. Because of we used animal model in this research, a statement about consent to participate is not applicable.

\section{Availability of data and materials}

I wish to share my data. All data and materials are available from the corresponding author on request.

\section{References}

1. Soewondo P, Ferrario A, Tahapary DL. Challenges in diabetes management in Indonesia: A literature review. Global Health. 
2013;9(1):63. https://doi.org/10.1186/1744-8603-9-63

\section{PMid:24299164}

2. Indonesian Ministry of Health. Laporan Nasional Riset Kesehatan Dasar 2018. The Indonesian Ministry of Health's National Research and Development Agency; 2019. Available from: http://www.labmandat.litbang.depkes.go.id/images/download/ laporan/rkd/2018/laporan_nasional_rkd2018_final.pdf. https:// doi.org/10.17501/24246735.2018.4105

3. Liang $H$, Ward WF. PGC-1 $\alpha$ : A key regulator of energy metabolism. Adv Physiol Educ. 2006;30(4):145-51.

PMid:17108241

4. Finck BN, Kelly DP. PGC-1 coactivators: Inducible regulators of energy metabolism in health and disease. $\mathrm{J}$ Clin Invest. 2006;116(3):615-22. https://doi.org/10.1172/jci27794 PMid:16511594

5. Puigserver P, Spiegelman BM. Peroxisome proliferatoractivated receptor-gamma coactivator 1 alpha (PGC-1 alpha): Transcriptional coactivator and metabolic regulator. Endocr Rev. 2003;24(1):78-90. https://doi.org/10.1210/er.2002-0012 PMid: 12588810

6. SetyawatiT.Peroxisome proliferatoractivated receptor $-\gamma($ Ppar- $-\gamma)$ coactivator $1-\alpha$ (PGC-1 $\alpha$ ) in type 2 Diabetes Mellitus and its role in mitochondrial function. Med Tadulako. 2014;1(1):54-62.

7. Corona JC, Duchen MR. PPAR gamma and PGC-1alpha as therapeutic targets in Parkinson's. Neurochem Res. 2015;40(2):308-16.

PMid:25007880

8. Wu H, Deng $X$, Shi $Y$, Su Y, Wei J, Duan H. PGC-1 $\alpha$, glucose metabolism and Type 2 diabetes mellitus. J Endocrinol. 2016;229(3):R99-115. https://doi.org/10.1530/joe-16-0021 PMid:27094040

9. Sugden MI, Caton PW, Holness MJ. PPAR control: It's SIRTainly as easy as PGC. J Endocrinol. 2010;204(2):93-104. https://doi. org/10.1677/joe-09-0359

PMid:19770177

10. Kim JA, Wei Y, Sowers JR. Role of mitochondrial dysfunction in insulin resistance. Circ Res. 2008;102(4):401-14. PMid:18309108

11. Łukaszuk B, Kurek K, Mikłosz A, Żendzian-Piotrowska M, Chabowski A. The role of PGC-1 $\alpha$ in the development of insulin resistance in skeletal muscle-revisited. Cell Physiol Biochem. 2015:37(6):2288-96. https://doi.org/10.1159/000438584 PMid:26625097

12. Li N, Brun T, Cnop M, Cunha DA, Eizirik DL, Maechler P. Transient oxidative stress damages mitochondrial machinery inducing persistentbeta-cell dysfunction. J Biol Chem. 2009;284(35):2360212. https://doi.org/10.1074/jbc.m109.024323 PMid:19546218

13. Mootha VK, Lindgren CM, Eriksson KF, Subramanian A, Sihag S, Lehar J, et al. PGC-1alpha-responsive genes involved in oxidative phosphorylation are coordinately downregulated in human diabetes. Nat Genet. 2003;34(3):267-73. https://doi.org/10.1038/ng1180 PMid: 12808457

14. Patti ME, Butte AJ, Crunkhorn S, Cusi K, Berria R, Kashyap S, et al. Coordinated reduction of genes of oxidative metabolism in humanswith insulin resistanceand diabetes: Potential role ofPGC1 and NRF1. Proc Natl Acad HICi USA. 2003;100(14):8466-71. https://doi.org/10.1073/pnas.1032913100 PMid:12832613

15. Puigserver $P$, Wu Z, Park CW, Graves R, Wright $M$, Spiegelman BM. Acold-inducible coactivator of nuclear receptors linked to adaptive thermogenesis. Cell. 1998;92(6):829-39. https://doi.org/10.1016/s0092-8674(00)81410-5

16. Leick L, Fentz J, Biensø RS, Knudsen JG, Jeppesen J, Kiens B, et al. PGC- $1 \alpha$ is required for AICAR-induced expression of
GLUT4 and mitochondrial proteins in mouse skeletal muHICle. Am J Physiol Endocrinol Metab. 2010;299(3):E456-65. https:// doi.org/10.1152/ajpendo.00648.2009

\section{PMid:20628026}

17. SafdarA, Little JP, StokIAJ, HettingaBP,AkhtarM, TarnopolskyMA Exercise increases mitochondrial PGC-1 $\alpha$ content and promotes nuclear-mitochondrial cross-talk to coordinate mitochondrial biogenesis. J Biol Chem. 2011;286(12):10605-17. https://doi. org/10.1074/jbc.m110.211466

PMid:21245132

18. Buler M, Aatsinki SM, Skoumal R, Komka Z, To M, Kerkela R, et al. Energy-sensing factors coactivator peroxisome proliferatoractivated receptor coactivator $1-\alpha(P G C-1 \alpha)$ and AMP-activated protein kinase control expression of inflammatory mediators in liver induction of interleukin 1 receptor antagonist. J Biol Chem. 2012;287(3):1847-60. https://doi.org/10.1074/jbc.m111.302356 PMid:22117073

19. Huang AM, Jen CJ, Chen HF, Yu L, Kuo YM, Chen HI. Compulsive exercise acutely upregulates rat hippocampal brain-derived neurotrophic factor. J Neural Transm (Vienna). 2006;113(7):803-11. https://doi.org/10.1007/s00702-005-0359-4

PMid:16252072

20. Kelley DE, He J, Menshikova EV, and Ritov VB. Dysfunction of mitochondria in human skeletal muscle in Type 2 diabetes. Diabetes. 2002;51(10):2944-50. https://doi.org/10.2337/diabetes.51.10.2944 PMid: 12351431

21. Liang $\mathrm{H}$, Balas $\mathrm{B}$, Tantiwong $\mathrm{P}$, Dube J, Goodpaster $\mathrm{BH}$ O'Doherty RM, et al. Whole body overexpression of PGC-1 $\alpha$ has opposite effects on hepatic and muscle insulin sensitivity. Am J Physiol Endocrinol Metab. 2009;296(4):E945-54. https:// doi.org/10.1152/ajpendo.90292.2008

PMid:19208857

22. Lin J, Handshin C, Spiegelman BM. Metabolic control through the PGC-1 family of transcription coactivators. Cell Metab. 2005;1(6):361-70.

PMid: 16054085

23. Marinho R, Mekary RA, Muñoz VR, Gomes RJ, Pauli JR, de Moura LP. Regulation of hepatic TRB3/Akt interaction induced by physical exercise and its effect on the hepatic glucose production in an insulin resistance state. Diabetol Metab Syndr. 2015;7:67. https://doi.org/10.1186/s13098-015-0064-x PMid:26288661

24. Huertas JR, Casuso RA, Agustín PH, Cogliati S. Stay fit, stay young: Mitochondria in movement: The role of exercise in the new mitochondrial paradigm. Oxid Med Cell Longev. 2019;2019:7058350. https://doi.org/10.1155/2019/7058350 PMid:31320983

25. Haase TN, Ringholm S, Leick L, Biensø RS, Kiilerich K, Johansen $\mathrm{S}$, et al. Role of PGC-1 $\alpha$ in exercise and fasting-induced adaptations in mouse liver. Am J Physiol Regul Integr Comp Physiol. 2011;301(5):R1501-9. https://doi.org/10.1152/ajpregu.00775.2010 PMid:21832205

26. Liang H, Bai Y, Li Y, Richardson A, Ward WF. PGC-1 $\alpha$-induced mitochondrial alterations in 3T3 fibroblast cells. Ann N Y Acad Sci. 2007;1100(1):264-79.

PMid: 17460188

27. Machrina Y, Harun AL, Purba A, Lindarto D. Effect various type of exercise to Insr gene expression, skeletal muscle insulin receptor and insulin resistance on diabetes mellitus type-2 model rats. Int J Health Sci. 2018;6(4):50-6.

28. Matiello R, Fukui RT, Silva ME, Rocha DM, Wajchenberg BL, Azhar $\mathrm{S}$, et al. Differential regulation of PGC-1 $\alpha$ expression in rat liver and skeletal muscle in response to voluntary running. Nutr Metab (Lond). 2010;7(1):36. https://doi.org/10.1186/1743-7075-7-36 PMid:20433743 